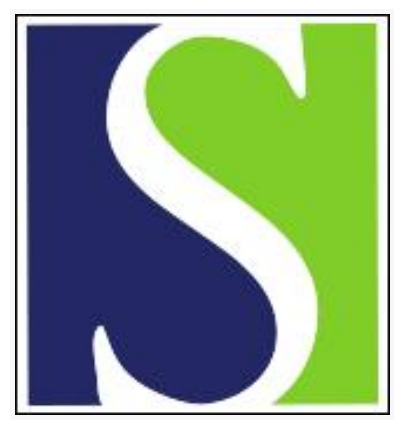

Scand J Work Environ Health 2014;40(4):390-399

https://doi.org/10.5271/sjweh.3421

Published online: 13 Mar 2014, Issue date: 01 Jul 2014

Walks4Work: Assessing the role of the natural environment in a workplace physical activity intervention

by Brown DK, Barton JL, Pretty J, Gladwell VF

This paper is the first to investigate the importance of natural environments in a workplace physical activity intervention. It provides evidence that a short walk in a natural environment twice a week can lower blood pressure and improve perceived mental health when compared to a built environment. Data suggests natural environments could be used to improve adherence to an intervention.

Affiliation: Daniel Brown, School of Biological Sciences, University of Essex, Wivenhoe Park, Colchester, C04 3SQ. dkbrow@essex.ac.uk

The following article refers to this text: 2019;45(6):533-545

Key terms: autonomic function; cardiovascular disease; green exercise; intervention; lunch break; mental well-being; natural environment; nature; physical activity; Walks4Work; workplace; workplace physical activity intervention

This article in PubMed: www.ncbi.nlm.nih.gov/pubmed/24623515

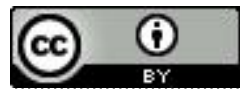




\title{
Walks4Work: Assessing the role of the natural environment in a workplace physical activity intervention
}

\author{
by Daniel K Brown, BSc, ${ }^{1}$ Jo L Barton, PhD, ${ }^{1}$ Jules Pretty, OBE, FSB, FRSA, ${ }^{1}$ Valerie F Gladwell, PhD ${ }^{1}$
}

\begin{abstract}
Brown DK, Barton JL, Pretty J, Gladwell VF. Walks4Work: Assessing the role of the natural environment in a workplace physical activity intervention. Scand J Work Environ Health. 2014;40(4):390-399. doi:10.5271/ sjweh.3421
\end{abstract}

\begin{abstract}
Objectives The primary aim of this study was to examine the impact of physical activity (PA) in the natural environment (eg, "green exercise") on resting autonomic function in the Walks4Work intervention. A secondary aim was to assess the feasibility of Walks4Work in terms of adherence, change in PA levels, and cardiovascular health parameters.

Methods In an 8-week randomized control trial, 94 office workers in an international company were allocated to one of three groups: control, nature (NW), or built (BW) lunchtime walking route. Both walking groups were required to undertake two lunchtime walks each week. The NW route centered around trees, maintained grass, and public footpaths. In contrast, the BW consisted of pavement routes through housing estates and industrial areas. Data were collected at baseline and following the intervention. To investigate the impact of the intervention, mixed-design analysis of variance (ANOVA) were performed.

Results A total of 73 participants completed the intervention (drop-out rate of $22 \%$ ). No difference was observed in resting autonomic function between the groups. Self-reported mental health improved for the NW group only. PA levels increased at the intervention mid-point for all groups combined but adherence to the intervention was low with rates of $42 \%$ and $43 \%$ within the BW and NW groups, respectively.

Conclusion Accompanying a guideline of two active lunchtimes per week with low facilitator input appears inadequate for increasing the number of active lunchtimes and modifying cardiovascular health parameters in an office population. However, this population fell within normal ranges for cardiovascular measures and future research should consider investigating at-risk populations, particularly hypertensive individuals.
\end{abstract}

Key terms autonomic function; cardiovascular disease; green exercise; lunch break; mental well-being; nature.

Cardiovascular disease (CVD) is one of the greatest sources of health risk in the UK, accounting for $39 \%$ of mortalities (1). Modifiable risk factors of CVD include hypertension, obesity, smoking, diabetes, and sedentary behavior. Stress, although not considered to be a direct risk factor of CVD, may also increase disease risk (2). The combination of stress alongside sedentary behavior is widespread in many workplaces. Therefore, workplace interventions specifically targeting sedentary behavior and stress may help alleviate some of the risks for CVD.

Individuals who do not engage in regular physical activity (PA) have a $20-30 \%$ greater risk for CVD (3), thus sedentary behavior has been identified as a key health issue (4). Regular walking promotes sustainable changes in PA and contributes to the achievement of recommended levels of moderate exercise (5), which subsequently benefits CVD risk profile (6). The workplace is a suitable location for incorporating PA interventions, such as walking, at a community level (7-9). Indeed, workplace interventions that include walking increase PA (10), but whether they decrease sedentary behavior is less clear. This concept has been identified in qualitative studies (11) with a systematic review identifying that sitting time is unaffected by workplace PA interventions (10). However, increasing activity during suitable periods of the day, such as lunchtime, provide opportunities for performing moderate activity (12) and may, thus, break up long periods of sedentary time.

Suitable outcome measures for assessing the health impact of a PA intervention have been highlighted as resting and exercising heart rate (HR), blood pressure (BP), CVD risk score, and aerobic fitness (13). Altera-

\footnotetext{
${ }^{1}$ School of Biological Sciences, University of Essex, Essex, United Kingdom.

Correspondence to: Daniel Brown, School of Biological Sciences, University of Essex, Wivenhoe Park, Colchester, CO4 3SQ. [E-mail dkbrow@essex.ac.uk]
} 
tions in HR that are observed with regular PA may in part be due to the adaptation of the autonomic nervous system (ANS) (14), which can be assessed using HR variability (HRV) - a well-established, non-invasive measure of vagal activity. A low HRV reflects reduced vagal activity and is linked to poor cardiovascular health (15). In addition, reductions in HRV have been linked with risk for cardiovascular mortality $(16,17)$, and stress has been shown to reduce HRV (18). Specifically, workplace stress has been identified as a contributing factor in increased risk for CVD (19), and reduced $\mathrm{HRV}$ is a characteristic of repeated exposure to stressful situations (20). How the ANS responds to, and recovers from, stress also offers an indication of cardiovascular health (21). Furthermore, stress indirectly contributes to modifiable CVD risk factors such as increased smoking, alcohol consumption, and importantly sedentary behavior (2), thus creating a detrimental cycle.

The lunch break is often a time when employees continue to remain at their workstations due to work demands or peer-pressure from colleagues. Thus a detrimental cycle of increased stress and sedentary behavior can prevail. The lunch period offers an opportunity to engage in moderate PA, interrupting long periods of sedentary time and providing an opportunity to decrease stress levels and restore physical and mental fatigue $(22,23)$.

The role of the exercise environment is one facet of workplace PA interventions not previously investigated that offers promise for enhancing health outcomes. Exercising in a natural environment could offer benefits above exercising in other settings. Amongst healthy, CVD-free populations, single exposures to natural environments can reduce mental fatigue and stress $(22,23)$, improve mental well-being (24-26), enhance ANS control measured as $\operatorname{HRV}(27,28)$, and reduce $\operatorname{BP}(27,29$, $30)$. Systematic reviews $(31,32)$ have highlighted that exercising in a natural environment (so-called "green exercise") improves mental well-being (eg, mood, selfesteem) more than indoor or urban area exercise. In addition, built environments may play a part in causing undesirable changes in cardiovascular measures, such as increased BP (33). Hartig et al (33) exposed participants to cognitively demanding tasks for 50 minutes before participants walked in either a nature reserve or a built urban environment for 30 minutes. When exposed to the urban environment, participant's systolic BP increased during the walk while a decrease in systolic BP was observed during the nature reserve walk. Thompson Coon et al's systematic review (32) found positive outcomes after only one exercise bout in a natural environment compared to an indoor setting. The authors concluded there is a limited amount of research investigating the impact of repeated exposure to the natural environment. Therefore, a workplace intervention that recognizes the role of the exercise environment offers a novel and multifaceted approach to improve employees' activity levels, workplace well-being, and health. Replicating measures associated with cardiovascular health, which have been employed by previous research investigating one-off bouts of green exercise, will allow longer-term impacts of green exercise to be investigated. Having seen changes in cardiovascular health measures after one-off bouts of green exercise, it might be expected that repeating exposure over a longer timeframe will have at least equal or perhaps greater effects. Thus, this is the first study to explore the physical health impact of a workplace lunchtime walking intervention program entitled Walks4Work.

The primary aim of this study was to examine the impact of the exercise environment on physical health outcomes of the Walks4Work intervention. The primary hypothesis is that walking in a natural environment will increase resting HRV and decrease resting HR more than walking in a built setting or not walking at all (control). The secondary hypothesis is that repeated walks in nature will positively impact on other physical markers of health, including CVD risk factors, BP, and autonomic responses to stress and increase perceived health. The third hypothesis is that lunchtime activity will increase among those participants allocated to a walking group. The secondary aim was to assess the feasibility of Walks4Work in terms of adherence and overall changes in PA levels to inform future work.

\section{Methods}

\section{Trial design}

This was a multi-workplace, parallel group study (with balanced randomization $[1: 1: 1]$ ) conducted in the UK (figure 1). There were two walking intervention groups and one control group. The lunchtime walking aspect of the intervention was intended to adhere to the UK government guideline daily levels of PA [ie, 30 minutes of moderate PA a day (34)]. In addition, it was important that the walk was achievable during the employees' 45-minute lunch break. Development of the intervention included feasibility discussions with the company's Managing Director and team leader of the health and well-being group. It was decided that the majority of the lunch break should remain unaffected by the intervention and five lunch breaks a week would be, in practical terms, too many for employees to achieve. Thus, 20 minutes ( $60 \%$ of the recommended daily 30 minutes of moderate PA) twice a week was considered the most feasible. The intervention consisted of an 8-week phase where participants were expected to complete two lunchtime walks every week. Both walking groups were asked to 


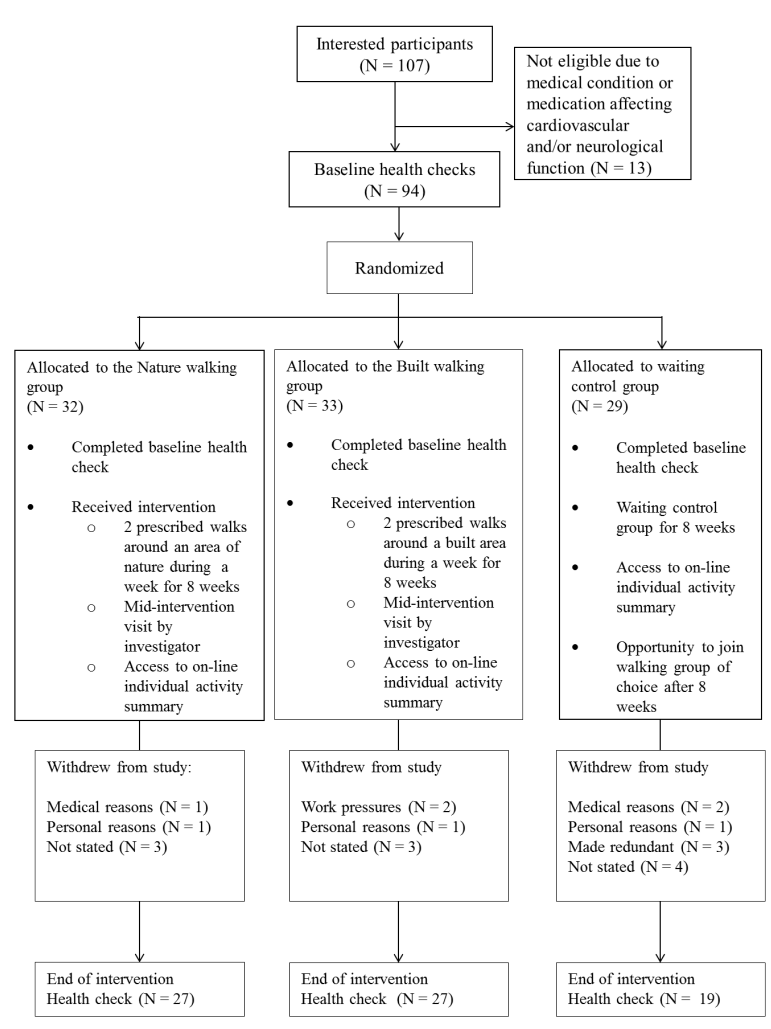

Figure 1. CONSORT participant flow diagram.

undertake a set circular walking route approximately $2 \mathrm{~km}$ in length, designed to provide a walk of approximately 20 minutes in duration. There were two circular routes: one for the nature walking (NW) group and the other for the built walking (BW) group. The route provided for the NW group consisted of trees, spaces of maintained grass, public footpaths, and country lanes. In contrast, the route for the BW group was primarily composed of paved footpaths adjacent to roads, housing estates, and industrial areas. Each participant was free to choose which two weekdays they walked in order to promote adherence. Additionally, participants were able to walk individually or with others. For full details of the intervention see Brown et al (35) (trial registration: ISRCTN05716448).

\section{Participants}

Recruitment of eligible participants was self-selecting in response to a request for companies to participate in a research project. Companies were required to be predominantly desk-based with a minimum of 200 employees to ensure that an adequate sample size could be achieved. Company employees were eligible to participate if they were 18-65 years of age and considered themselves healthy and able to undertake fairly intense exercise. Exclusion criteria were known cardiovascular and/or neurological conditions or taking of medication that affects these systems. Exclusion criteria were assessed with participant self-ratings after discussion with investigators where appropriate.

The participating company was an international Financial Times and London Stock Exchange (FTSE) 100 company, which has several sites within the UK. In the current study, two sites were used with a total combined workforce of 378, where main job roles consisted of contract driven work, predominantly desk-based with the addition of some manual aspects.

Physiological data were collected onsite and psychological questionnaires completed online. During the intervention, participants were "self-walking" (ie, no prompt from researchers to complete the required two weekly walks). Eligible participants were recruited in April 2011, with health checks and questionnaires completed at baseline (last two weeks of April 2011) and following the 8-week intervention (July 2011).

\section{Outcomes}

The primary outcome measures were HR and natural log of high frequency (lnHF) values to explore changes in vagally mediated HRV following the intervention. Baseline and follow-up health checks were carried out onsite in sessions with $\leq 8$ participants at any one time, within the testing room. Participants completed a consent form and the pre-exercise screening questionnaire and were then fitted with two HR monitors. A Polar HR monitor (Polar Electro UK Ltd, Warwick, UK) was used to view HR throughout the testing procedure. The other HR recorder (eMotion sensor, Megaemg, University of Kuopio, Finland) had no visual display and was used to assess each heart beat to explore HRV. Stature (m), body mass $(\mathrm{kg})$ and waist circumference $(\mathrm{cm})$ were also recorded. Participants remained seated (except during a sub-maximal fitness test) facing away from each other, with space between to minimize any interference. A resting BP measurement was taken using an electronic BP monitor (MX3 basic, Omron, Lake Forest, IL, USA) with the cuff placed on the participant's upper right arm. The health check also consisted of a rest period, a stressful task, and a sub-maximal fitness test (described below). Further detail of the health checks can be found in Brown et al (35).

At each health check, HR data was collected during a 5-minute rest period. Additional HR data was collected during a stressor and recovery from the stressor (HR stress recovery) period, each lasting three minutes. The stressor consisted of a serial subtraction task with a socioevaluative threat element. In brief, the participants completed a 3-minute stressor comprising a mental arithmetic challenge of subtracting a 2-digit from a 4-digit number. The same 2-digit number was then 
subtracted from each consecutive answer. Participants were asked to repeat the process as quickly as possible for a period of three minutes. During this time, they were instructed to write down only the answer (no calculations) and not to look back at the previous answer. They were told the longest sequence of correct answers would be calculated. To induce a further socioevaluative threat, participants were observed by the researchers who walked around the room. A verbal countdown was given at "half-way", "1 minute to go", "30 seconds remaining" and "10 seconds left" to increase pressure (35). Physiological stress response was calculated as the change from resting values (stress value - resting value) as was recovery from stress (recovery value - resting value). This was repeated for $\mathrm{HR}$ and $\operatorname{lnHF}$ values.

Secondary outcome measures included the Framingham CVD risk score (\%), calculated using the General CVD (10-year risk) calculator (available at (www.framinghamheartstudy.org) (36). This does not calculate a CVD risk for those $<30$ years old $(\mathrm{N}=15$ in current study). Further measures included: systolic and diastolic BP, predicted aerobic fitness [from Chester step test (37)], and body mass index (BMI).

The SF-8 health questionnaire was used to assess participants' perceived general, mental, and physical health using the SF- $8^{\circledR}$ Health Survey. PA was objectively measured and quantified as steps using activity monitors (ActiPed, Fitlinxx Inc, Shelton, CT, USA). Daily worktime PA was calculated as mean daily (09:00-17:00 hours) step count from Monday to Friday. The ActiPed picks up any activity involving the lower body (38) and participants were instructed to wear the monitor for all waking hours. Therefore a zero activity count for the day (of particular relevance, including outside work hours) signifies non-compliance with wearing the activity monitor. Such days do not represent sedentary behavior but, rather, unknown activity and are subsequently excluded from the calculation of mean daily steps. Lunchtime activity was assessed as number of active lunchtimes per week (Monday to Friday), defined as $\geq 1500$ steps completed in a 45-minute period between 12:00-14:00 hours. This was chosen as a conservative absolute minimum for a continuous bout of PA that might straddle two 20-minute epochs. Additionally, the routes were circular making it likely that participants would complete the full walk.

\section{Sample size}

As HR and lnHF are markers of health, these parameters were used in the power calculation to assess the number of participants required for the study. Additionally, sample size was based on the inclusion of three groups in the study (NW, BW, and a control). From previous studies assuming a relevant difference of -5.0 [standard deviation (SD) 5.0] HR, 0.6 (SD 0.5) lnHF, and a sig- nificance level of $\alpha=0.05$, statistical power of $80 \%$ and associated Bonferroni adjustments, a final group size of $\mathrm{N}=24$ was required. However, it was expected that $30 \%$ of participants would not comply with the study protocol, which may be due to unusable data (including incomplete data, technical failure), drop-outs, and non-finishers due to intervention and/or the follow-up period. Therefore, approximately 32 participants were required per group: a total of 100 participants. Previous studies that have measured an effect of environment on physiological variables have used between 16-29 participants $(27,28)$.

\section{Randomization}

After enrolment, participants were assigned to one of three groups following simple randomization procedures (computerized random numbers). Groupings were only known to the researchers and participants following the baseline health checks in order for researcher bias to be eliminated.

\section{Blinding}

Participants were informed only about their specific intervention. However, contamination between groupings could occur as participants from all three groups worked in the same office building and discussed the project amongst themselves.

\section{Heart rate variability analysis}

Each heart beat was recorded using an eMotion sensor (Megaemg, University of Kuopio, Kuopio, Finland) to assess HRV. This data was averaged into three 3-minute segments: at rest, during stress, and during recovery from stress (HR stress recovery) for each participant. Data were collected at baseline and follow-up health checks. Power spectral analysis was used to determine the high frequency component $(0.15-0.4 \mathrm{~Hz})$ of HRV All HRV analysis was performed using Kubios Pro software (University of Kuopio, Kuopio, Finland) (39).

\section{Statistical analysis}

To test the primary hypothesis, a mixed-design analysis of variance (ANOVA) was used to examine autonomic function (HR and high frequency component) across all three groups over the intervention. Secondary hypotheses were tested using mixed-design ANOVA on systolic and diastolic BP, CVD risk, BMI, and fitness. Additional mixed-design ANOVA were used to explore self-reported health data across all groups over the intervention. To explore the secondary aim of the study, qualitative analysis was performed on mean active lunchtimes per week 
to determine adherence. A mean of $\geq 2$ was considered to be successful adherence to the allocated two active lunchtimes in the walking intervention. Overall PA was assessed at baseline, mid-intervention, and end of intervention using mean daily (09:00-17:00 hours) step count. This was analyzed using a mixed-design ANOVA. An alpha level of $<0.05$ was considered significant. Mean differences with $95 \%$ CI were calculated to assess the magnitude of change. Where $95 \% \mathrm{CI}$ did not cross zero, a meaningful change was considered to have occurred (40). Post-hoc pairwise comparisons with Bonferroni correction were applied where appropriate with adjusted alpha levels for within-subject variables. All data were normally distributed (as assessed by Kolomogorov-Smirnov) apart from the HF component of HRV, which was natural log transformed prior to statistical analysis. All analysis was performed using SPSS PASW version 18 (IBM Corp, Armonk, NY, USA).

\section{Results}

A one-way between-subjects ANOVA showed no differences in baseline values for the primary outcome variables of resting HR and lnHF. Secondary outcomes of systolic and diastolic BP, all HR and lnHF variables, BMI, CVD risk, predicted fitness, and SF-8 measures did not differ at baseline.

With regards to the primary hypothesis, neither resting HR nor lnHF (table 2) demonstrated significant changes due to group allocation (tables 1 and 2). Regarding autonomic function during an acute mental stress, no interaction effect was observed between group and time.

Exploring the secondary measures of health, a mixeddesign ANOVA identified a group $\times$ time interaction for mean systolic BP over the intervention. A reduction in systolic BP was seen in both the control and NW group of -7.2 (95\% CI - 11.5- -2.8) mmHg and -5.7 (95\% CI -8.9$-2.5) \mathrm{mmHg}$, respectively, whilst the BW group showed only a small change of 0.7 (95\% CI $-3.0-4.5) \mathrm{mmHg}$. Importantly, exploring the baseline values identifies that the control and NW groups started with a mean systolic $\mathrm{BP}$ of $\sim 5 \mathrm{mmHg}$ greater than that of the BW group. No other significant interactions existed for other physiological markers of health BMI, CVD risk score, or aerobic fitness. Mixed-design ANOVA revealed a main effect of time for decreased diastolic BP, CVD risk, HR response to stress, and HR recovery from stress, irrespective of exercise environment. Additionally diastolic BP showed a main effect for group with participants in the NW group reporting greater diastolic BP.

Mixed-design ANOVA revealed an interaction effect for self-reported mental health (table 2). Confidence intervals identify the mean score in the NW group to have
Table 1. Demographic data for the study participants. [BMl=body mass index; SD=standard deviation]

\begin{tabular}{|c|c|c|c|c|c|c|c|c|}
\hline & \multicolumn{8}{|c|}{ Group } \\
\hline & \multicolumn{2}{|c|}{ Total } & \multicolumn{2}{|c|}{ Control } & \multicolumn{2}{|c|}{ Built } & \multicolumn{2}{|c|}{ Nature } \\
\hline & Mean & SD & Mean & SD & Mean & SD & Mean & SD \\
\hline Age (years) & 42.0 & 10.6 & 40.2 & 11.0 & 39.3 & 10.3 & 46.3 & 9.4 \\
\hline Male & 74 & & 24 & & 24 & & 26 & \\
\hline Female & 20 & & 5 & & 9 & & 6 & \\
\hline \multicolumn{9}{|l|}{ Ethnicity (British) } \\
\hline White & 92 & & 29 & & 31 & & 32 & \\
\hline Indian & 2 & & 0 & & 2 & & 0 & \\
\hline \multicolumn{9}{|l|}{ Smoking status } \\
\hline Smoker & 0 & & 0 & & 0 & & 0 & \\
\hline Non-smoker & 94 & & 29 & & 33 & & 32 & \\
\hline $\mathrm{BMI}\left(\mathrm{kg} / \mathrm{m}^{2}\right)$ & 26.3 & 3.3 & 26.3 & 3.5 & 27.3 & 3.5 & 25.6 & 2.6 \\
\hline $\begin{array}{l}\text { Predicted aerobic } \\
\text { fitness }(\mathrm{ml} / \mathrm{kg} / \mathrm{min}-1)\end{array}$ & 39.8 & 8.1 & 39.2 & 7.9 & 40.1 & 6.3 & 39.1 & 9.0 \\
\hline
\end{tabular}

increased above baseline scores by 2.7 (95\% CI 0.0-5.4) whilst the control group and BW group did not [-3.3 (95\% CI -6.3-0.3) and -0.3 (95\% CI -4.3-3.8), respectively]. No interaction effect was found for components of selfreported general health or physical health.

\section{Active lunchtimes}

Figure 2 presents the mean number of active lunchtimes ( $\geq 1500$ steps during 12:00-14:00 hours) per week for all study groups. At baseline, all groups were below a mean number of two active lunchtimes a week. Initially, both intervention groups increased their mean active lunchtimes above two per week. For the BW group this mean remained above two per week until after week 3 . The NW intervention sustained a mean number of active lunchtimes above two per week until week 4. During weeks $5-8$, mean active lunchtimes remained below two per week for both intervention groups. The control group showed a mean number of active lunchtimes below two per week throughout the entire intervention and active lunchtimes remained below the walking groups at each time-point. Overall, $43 \%$ and $42 \%$ of participants in the BW and NW groups, respectively, achieved the target of two lunchtime walks per week, whilst only $13 \%$ of the control group completed two lunchtime walks a week during the intervention period.

The achievement of the allocated two walks would add, as a minimum, an extra 3000 steps per week. In terms of mean daily activity, these additional steps would equate to an extra 600 steps per day. The NW group showed the highest peak of mean daily steps (figure 3) with an increase of 745 steps/day. The BW and control groups showed a mean increase of 374 and 217 steps/day respectively. Thus the NW group was the only group, on average, to achieve the targeted increase in mean daily activity via lunchtime walks. Regarding 
Table 2. Primary and secondary health outcome measures at baseline $\left(T_{B}\right)$ and end of intervention $\left(T_{E N D}\right)$ for nature walking, built walking, and control group. [Change from baseline is shown $\left(\Delta \mathrm{T}_{\mathrm{END}} \mathrm{T}_{\mathrm{B}}\right)$ with $95 \%$ confidence intervals $(95 \% \mathrm{Cl})$. $\mathrm{F}$ statistics for interaction effect (Group $\times$ Time), main effect for time and group are reported with significance level where appropriate. [BMI=body mass index; HR=heart rate; InHF=natural log of high frequency component; $\mathrm{BP}=$ blood pressure; $\mathrm{CVD}=$ cardiovascular disease.] Benefits to health may occur with decreases in HR, SBP, DBP, BMI, CVD, HR stress response, HR stress recovery, and increases in fitness, InHF (rest, stress and recovery), and SF-8 general, physical and mental health.

\begin{tabular}{|c|c|c|c|c|c|c|c|c|c|c|}
\hline & \multirow[t]{2}{*}{$\mathrm{N}$} & \multicolumn{2}{|c|}{$\mathrm{T}_{\mathrm{B}}$} & \multicolumn{2}{|c|}{$\mathrm{T}_{\mathrm{END}}$} & \multirow[t]{2}{*}{$\Delta T_{E N D}-T_{B}$} & \multirow[t]{2}{*}{$95 \% \mathrm{Cl}$} & \multicolumn{3}{|c|}{ F statistic } \\
\hline & & Mean & SD & Mean & SD & & & Group $\times$ Time & Time & Group \\
\hline \multicolumn{11}{|c|}{ HR resting (bpm) } \\
\hline Nature & 27 & 67.1 & 10.0 & 68.3 & 11.6 & 1.1 & $-2.6-4.9$ & 0.30 & 0.35 & 1.01 \\
\hline Built & 27 & 63.6 & 10.1 & 65.1 & 10.4 & 1.5 & $-2.5-5.5$ & & & \\
\hline Control & 19 & 64.6 & 12.5 & 64.0 & 11.2 & -0.6 & $-5.0-3.7$ & & & \\
\hline \multicolumn{11}{|c|}{ InHF resting } \\
\hline Nature & 23 & 5.3 & 1.7 & 5.2 & 1.6 & -0.1 & $-0.6-0.3$ & 0.02 & 1.00 & 2.00 \\
\hline Built & 24 & 5.9 & 1.3 & 5.7 & 1.5 & -0.2 & $-0.7-0.3$ & & & \\
\hline Control & 18 & 6.1 & 1.1 & 6.0 & 1.6 & -0.1 & $-1.0-0.7$ & & & \\
\hline \multicolumn{11}{|c|}{ Systolic BP (mmHg) } \\
\hline Nature & 27 & 135.1 & 12.3 & 129.3 & 10.3 & -5.7 & $-8.9--2.5$ & $5.53^{\text {a }}$ & $14.78^{b}$ & 0.48 \\
\hline Built & 27 & 128.9 & 15.1 & 129.7 & 14.2 & 0.7 & $-3.0-4.5$ & & & \\
\hline Control & 19 & 133.3 & 10.5 & 126.1 & 10.7 & -7.2 & $-11.5--2.8$ & & & \\
\hline \multicolumn{11}{|c|}{ Diastolic BP (mmHg) } \\
\hline Nature & 27 & 86.0 & 7.6 & 82.6 & 7.0 & -3.4 & $-5.8--1.0$ & 1.00 & $11.82^{b}$ & $4.00^{c}$ \\
\hline Built & 27 & 81.5 & 11.9 & 80.1 & 11.6 & -1.4 & $-4.5-1.8$ & & & \\
\hline Control & 19 & 79.5 & 7.1 & 75.1 & 6.8 & -4.4 & $-8.5--0.2$ & & & \\
\hline \multicolumn{11}{|c|}{$\mathrm{BMI}\left(\mathrm{kg} / \mathrm{m}^{2}\right)$} \\
\hline Nature & 28 & 25.6 & 2.6 & 25.5 & 2.6 & -0.1 & $-0.2-0.1$ & 0.66 & 2.54 & 1.91 \\
\hline Built & 24 & 27.3 & 3.7 & 27.2 & 3.8 & -0.0 & $-0.3-0.2$ & & & \\
\hline Control & 20 & 25.9 & 3.5 & 25.7 & 3.5 & -0.2 & $-0.5-0.2$ & & & \\
\hline \multicolumn{11}{|c|}{ CVD risk (\%) } \\
\hline Nature & 27 & 9.0 & 4.4 & 8.5 & 4.4 & -0.5 & $-1.0--0.1$ & 1.75 & $13.34^{b}$ & 0.32 \\
\hline Built & 20 & 8.2 & 6.2 & 8.0 & 6.0 & -0.2 & $-0.6-0.3$ & & & \\
\hline Control & 15 & 8.0 & 4.6 & 7.1 & 4.1 & -0.9 & $-1.6--0.8$ & & & \\
\hline \multicolumn{11}{|c|}{$\begin{array}{l}\text { Predicted aerobic fitness } \\
(\mathrm{ml} / \mathrm{kg} / \mathrm{min}-1)\end{array}$} \\
\hline Nature & 24 & 39.0 & 9.5 & 39.3 & 5.9 & 0.3 & $-2.9-3.5$ & 0.52 & 0.88 & 0.29 \\
\hline Built & 23 & 39.8 & 6.8 & 39.8 & 5.5 & 0.0 & $-2.7-2.8$ & & & \\
\hline Control & 19 & 39.6 & 7.7 & 41.7 & 7.2 & 2.1 & $-1.3-5.5$ & & & \\
\hline \multicolumn{11}{|c|}{ HR stress response (bpm) } \\
\hline Nature & 23 & 16.0 & 11.7 & 10.2 & 8.7 & -5.9 & $-8.5--3.2$ & 0.79 & $50.86^{b}$ & 2.11 \\
\hline Built & 24 & 10.8 & 8.6 & 6.0 & 5.2 & -4.7 & $-7.3--2.2$ & & & \\
\hline Control & 18 & 15.2 & 8.2 & 7.8 & 7.9 & -7.4 & $-11.4--3.3$ & & & \\
\hline \multicolumn{11}{|c|}{ HR stress recovery (bpm) } \\
\hline Nature & 23 & 5.3 & 6.4 & 2.4 & 3.5 & -2.9 & $-5.0--0.8$ & 0.95 & $8.83^{a}$ & 1.61 \\
\hline Built & 24 & 2.5 & 3.8 & 1.5 & 2.7 & -1.0 & $-2.7-0.6$ & & & \\
\hline Control & 18 & 4.0 & 4.2 & 2.6 & 4.7 & -1.4 & $-4.3-1.5$ & & & \\
\hline InHF stres & & & & & & & & & & \\
\hline Nature & 23 & -0.3 & 1.1 & -0.1 & 1.1 & 0.2 & $-0.4-0.8$ & 0.11 & 2.42 & 1.81 \\
\hline Built & 24 & -0.4 & 1.3 & -0.1 & 1.1 & 0.3 & $-0.4-0.9$ & & & \\
\hline Control & 18 & -0.9 & 1.4 & -0.5 & 1.0 & 0.4 & $-0.5-1.3$ & & & \\
\hline InHF stres & & & & & & & & & & \\
\hline Nature & 23 & 0.2 & 1.0 & 0.3 & 0.5 & 0.1 & $-0.4-0.6$ & 0.33 & 0.86 & 0.60 \\
\hline Built & 24 & 0.1 & 0.7 & 0.3 & 1.0 & 0.3 & $-0.3-0.8$ & & & \\
\hline Control & 18 & 0.02 & 0.6 & 0.03 & 0.9 & 0.01 & $-0.4-0.5$ & & & \\
\hline SF-8 gene & & & & & & & & & & \\
\hline Nature & 25 & 47.9 & 7.1 & 50.2 & 5.2 & 2.3 & $-0.8-5.4$ & 0.84 & 1.99 & 0.36 \\
\hline Built & 16 & 48.2 & 7.4 & 50.5 & 4.7 & 2.3 & $-0.9-5.4$ & & & \\
\hline Control & 19 & 48.2 & 5.7 & 47.8 & 6.5 & -0.4 & $-4.5-3.7$ & & & \\
\hline SF-8 physi & & & & & & & & & & \\
\hline Nature & 25 & 54.1 & 4.5 & 54.9 & 2.9 & 0.8 & $-0.7-2.3$ & 0.15 & 0.83 & 2.70 \\
\hline Built & 16 & 50.4 & 7.2 & 51.8 & 5.5 & 1.4 & $-3.7-6.5$ & & & \\
\hline Control & 19 & 53.2 & 7.7 & 53.4 & 4.7 & 0.2 & $-2.9-3.2$ & & & \\
\hline SF-8 ment & & & & & & & & & & \\
\hline Nature & 25 & 50.3 & 6.3 & 53.0 & 6.1 & 2.7 & $0.0-5.4$ & $4.35^{c}$ & 0.11 & 0.70 \\
\hline Built & 16 & 50.3 & 9.7 & 50.1 & 9.8 & -0.3 & $-4.3-3.8$ & & & \\
\hline Control & 19 & 50.7 & 9.2 & 47.4 & 8.2 & -3.3 & $-6.3-0.3$ & & & \\
\hline
\end{tabular}

a $P<0.01$.

b $P<0.001$.

${ }^{c} \mathrm{P}<0.05$. 
overall activity between 09:00-17:00 hours (figure 3), a mixed-design ANOVA showed a significant main effect for time $\left(\mathrm{F}_{2,2}=3.47, \mathrm{P}<0.05\right)$. Pairwise comparisons identified a rise in mean daily step count, independent of group, at the intervention mid-point (week 4) compared to baseline $(\mathrm{P}<0.05)$ and end of intervention $(\mathrm{P}<0.05)$.

\section{Discussion}

Previous literature has observed improvements in HRV following one-off exercise bouts in nature (30). This study was the first to investigate whether markers of autonomic function changed after an 8-week walking program was introduced as a lunchtime intervention within a workplace setting. It was hypothesized that

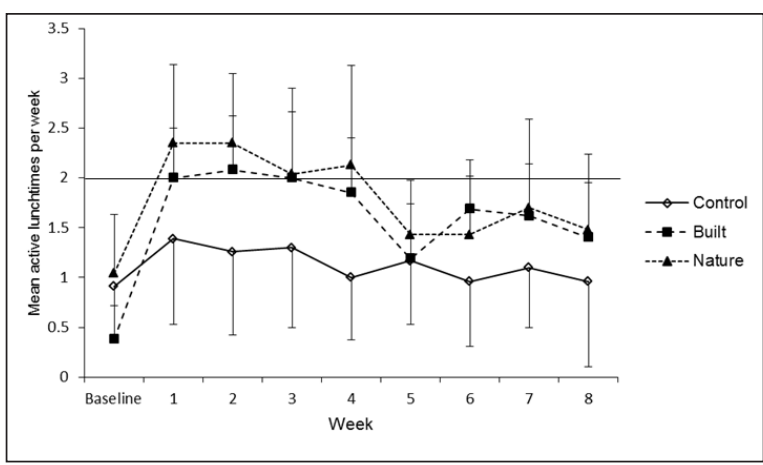

Figure 2. Mean ( $95 \%$ confidence interval) active lunchtimes for control and built and nature walking groups at baseline and over the 8-week intervention period. Two active lunchtimes represents achievement of intervention.

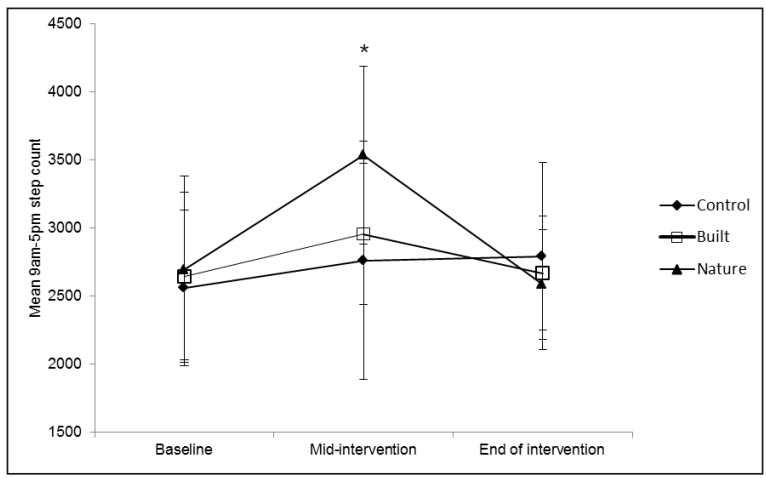

Figure 3. Mean (95\% confidence interval) daily (09:00-17:00 hours) step count at baseline, mid-point and end of intervention. * Significantly different to baseline and end of intervention $(P<0.05)$. walking in a natural environment would increase HRV and decrease HR at rest more than walking in a built setting or not walking at all as previously reported in environmental studies $(27,28,30)$ and after PA (41). The hypothesis is rejected as no differences in either resting HRV or HR were observed. No difference was observed in HRV in response to, or recovery from, an acute mental stressor. Thus, the previous findings of HRV changes following one-off bouts of green exercise were not replicated in this study.

Systematic reviews have identified that low resting HRV is a biomarker of workplace stress (42). However, in the current study, participants did not exhibit resting levels of HRV previously attributed to individuals suffering from chronic stress. Baseline values for lnHF were greater than those identified in the systematic review; this might be, in part, why no changes in ANS function were observed (ie, they already had good autonomic function).

Previous research measuring BP has robustly shown greater reductions in BP following acute exposure to natural compared to built environments $(27,29,30)$ and thus it may be suggested that this would also occur (and perhaps be enhanced) following repeated exposures over a period of time. This study identified there was an interaction for groups. The mean systolic BP for NW and control groups decreased at the end of the intervention. This was not the case for the BW group. However, this finding should be considered with caution as baseline levels of systolic BP in the BW group were lower than that of the control and NW groups, who displayed pre-hypertensive values $(>130$ $\mathrm{mmHg}$ ). These pre-hypertensive levels may increase the likelihood of observing a decrease in mean systolic BP at the end of the intervention. Furthermore, the level of activity prescribed in the Walks4Work intervention might not have been a sufficient stimulus to shift baseline BP within normal ranges. Therefore, it would be unwise to suggest that the walking intervention was ineffective as it is possible that two walks per week over an 8-week period is insufficient in a population with normative BP values. It would be of interest to repeat the study using hypertensive participants.

Proposed reasons for the decrease in BP in previous studies exploring acute exposure include alterations in psychological factors such as the relaxation and restorative qualities of natural environments $(22,43,44)$ which, conversely, are thought to be absent from built environments. Interestingly, in the current study, we noted improvements in mental well-being for the NW but not the BW intervention group, supporting the argument for the psychological benefits of nature alone (26). Research from Japan posits that physical components of natural environments play an important role in lowering BP through reductions in adrenaline and sympathetic activity (27). However, the current study does not show any measurable changes in the ANS. Differences in the 
landscapes between the current study and the research in Japan should be noted; in particular the Japanese research predominantly took place in a conifer forest in comparison to the UK parkland of the current study.

In this study, the effect on other physiological measures (eg, HR and HRV during rest, stressor, and recovery from a stressor) were not significantly different between the intervention groups. Measurements were not taken immediately following the nature walk. Therefore the study did not examine the possibility that the acute physiological changes occurred but did not aggregate to produce longer-term changes. Conversely, it may be that the stimulus (eg, two 20-minute walks per week) was simply insufficient to evoke such changes. Furthermore, it may be that the measures employed were not sensitive enough to identify statistically significant changes as in part they were looking at more centrally mediated changes in the ANS, whereas local changes may be occurring. Other recent research (45) suggests that an 8-week green exercise intervention may be sufficient to evoke local vascular remodeling changes. Thompson et al analyzed blood samples to identify changes in components utilized in building the extracellular matrix of the vascular walls. These measures appear promising and may be useful in future studies.

Exploratory analysis revealed that adherence to the intervention was low. There was an increase in selfreported mental health in the NW group. However, with low adherence in all walking groups, the hypothesis that repeated walks in nature would increase mental health cannot be fully accepted.

\section{Feasibility}

The secondary aim of the study was to assess the feasibility of the Walks4Work program with regard to incorporating walking outside the office into a lunchtime period.

Both NW and BW groups altered their behavior at lunchtime with the walking intervention ( $\geq 2$ active lunchtimes), and this appeared to be maintained for one week longer with those walking in nature. Although adherence rates were disappointing, this intervention showed $42 \%$ and $43 \%$ of the BW and NW groups, respectively, adhered to twice weekly walks - despite low facilitator input. After the mid-point of the intervention, mean number of lunchtime walks in both intervention groups were below the target of two walks. It is possible that this drop in adherence reflected either a decline in motivation to walk at lunchtime or boredom with walking the same route twice a week. Although not measured directly in this study, motivation and intention to change is an important factor eliciting longer-term behavior change $(46,47)$. More than the mere provision of walking routes, PA monitoring and an expectation to actually complete the walks seems necessary to encour- age office workers to be physically active at lunchtime. In addition, it may be useful to include a motivational component to help participants maintain adherence, particularly those who were the most sedentary and most likely to return to their previous sedentary behavior, especially with increasing work pressures. This finding should be considered in development of future programs aimed at longer-term adherence, which may lead to increased health gains.

The purpose of the walks was to increase PA levels and allow participants to engage with their environment without input from a researcher. In addition, this approach examined the efficacy of a PA intervention with limited resource requirements (eg, walk leaders), thus decreasing costs but not necessarily improving cost-effectiveness. In future, the walking route should be regularly screened as many participants mentioned obstacles such as overgrown vegetation on the NW. Although this study aimed to investigate the impact of exercise environments and consequently routes were kept consistent to meet environmental criteria, workplaces may find it useful to establish a greater range of walks. The routes chosen were the most appropriate in the immediate surrounding area, which allowed for the greatest differences between natural and built environments.

\section{Limitations}

Although this study was the first randomized controlled trial in this area of research, it had some limitations. Firstly, as group allocation was randomized, drop-out rates were expected to be equal across the study groups. However, the final number in the control group was lower than anticipated and thus the statistical power of the results was reduced. In future studies, a more conservative drop-out rate of $40 \%$ may be appropriate. Secondly, the health check may not be sensitive enough to pick up subtle differences between the walking environments. Further to this, the 3-minute stress test is short and only provoked a mild stress response, although this varied with individuals (as noted by HR response). The stress test was designed to fit within the available time given by the company. However, a longer but more potent stress test, including public-speaking and cognitive challenges, would increase the likelihood of identifying subtle changes in cardiovascular stress responses. It would also be of use to include work-related measures such as job strain, mood, and fatigue.

In the current study, the ActiPed was used for remote collection of data and the objective assessment of PA for the working day between 09:00-17:00 hours. The study did not account for PA occurring outside worktime. Although participants were asked to wear the ActiPed at all times, often it was difficult to identify whether they had forgotten to wear it or were being sedentary. There- 
fore PA outside of working hours was considered unreliable and not included, this means possible confounding variables such as leisure-time PA and differences in sedentary behavior may have influenced the results. Furthermore, the ActiPed did not detect some types of activity (ie, cycling, swimming). These problems are inherent with pedometers, but the advantage of using the ActiPed is that data can be collected remotely for up to five months. As the participant is not required to manually record daily step counts, data collection can be more accurate than other methods.

\section{Concluding remarks}

Providing the guideline of two active lunchtimes a week with feasible low facilitator input appears inadequate for increasing the number of active lunchtimes in an office population. Furthermore, the exercise environment does not seem to influence activity levels or health outcomes. Providing motivation at regular intervals might improve adherence to the intervention. Further research is recommended in order to understand the potential role of lunchtime workplace PA interventions in different environments to modify ANS function, BP, and enhance mental health, particularly among highly stressed or hypertensive individuals.

\section{Acknowledgments:}

We would like to thank J Suddaby for her help with data collection. The British Heart Foundation (non-clinical $\mathrm{PhD}$ studentship FS/10/32/28204) and Economic and Social Research Council (project number RES-064-270019) supported this study.

\section{References}

1. Nichols M, Townsend N, Luengo-Fernandez R, Leal J, Gray A, Scarborough P, et al. European Cardiovascular Disease Statistics. European Heart Network, Brussels, European Society of Cardiology, Sophia Antipolis; 2012 Sep.

2. Chandola T, Britton A, Brunner E, Hemingway H, Malik M, Kumari M, et al. Work stress and coronary heart disease: what are the mechanisms? Eur Heart J. 2008;29:640-8. http:// dx.doi.org/10.1093/eurheartj/ehm584.

3. World Health Organization (WHO). Global recommendations on physical activity for health. Geneva: WHO; 2010

4. Kohl HW, Craig CL, Lambert EV, Inoue S, Alkandari JR, Leetongin G, et al. The pandemic of physical inactivity: global action for public health. Lancet. 2012;380:294-305. http:// dx.doi.org/10.1016/S0140-6736(12)60898-8.
5 Welk GJ, Blair SN, Wood K, Jones S, Thompson RW. A comparative evaluation of three accelerometry-based physical activity monitors. Med Sci Sports Exerc. 2000;32:S489-97. http://dx.doi.org/10.1097/00005768-200009001-00008.

6. Murtagh EM, Murphy MH, Boone-Heinonen J. Walking: the first steps in cardiovascular disease prevention. Curr Opin Cardiol. 2010;25:490-6.http://dx.doi.org/10.1097/ HCO.0b013e32833ce972.

7. Miller R, Brown W. Steps and sitting in a working population. Int J Behav Med. 2004;11:219-24. http://dx.doi.org/10.1207/ s15327558ijbm1104_5.

8. National Institute for Health and Care Excellence (NICE). Promoting mental wellbeing through productive and healthy working conditions: public health guidance 22 for employers. London, United Kingdom. NICE; 2009.

9. Heath GW, Parra DC, Sarmiento OL, Andersen LB, Owen $\mathrm{N}$, Goenka S, et al. Evidence-based intervention in physical activity: lessons from around the world. Lancet. 2012;380:27281. http://dx.doi.org/10.1016/S0140-6736(12)60816-2.

10. Chau JY, der Ploeg HP, van Uffelen JG, Wong J, Riphagen I, Healy GN, et al. Are workplace interventions to reduce sitting effective? A systematic review. Prev Med. 2010;51:352-6. http://dx.doi.org/10.1016/j.ypmed.2010.08.012.

11. Gilson ND, Burton NW, van Uffelen JG, Brown WJ. Occupational sitting time: employees perceptions of health risks and intervention strategies. Health Promot J Austr. 2011;22:38-43.

12. Bupa. Reclaim the lunchbreak. London: Bupa; 2010

13. King N, Hopkins M, Caudwell P, Stubbs R, Blundell J. Beneficial effects of exercise: shifting the focus from body weight to other markers of health. Br J Sports Med. 2009;43:924-7. http:// dx.doi.org/10.1136/bjsm.2009.065557.

14. Seals DR, Chase PB. Influence of physical training on heart rate variability and baroreflex circulatory control. J Appl Physiol. 1989; 66:1886-95.

15. Thayer JF, Lane RD. The role of vagal function in the risk for cardiovascular disease and mortality. Biol Psychol. 2007;74:224-42. http://dx.doi.org/10.1016/j. biopsycho.2005.11.013.

16. Tsuji H, Venditti FJ, Jr., Manders ES, Evans JC, Larson MG, Feldman CL, et al. Reduced heart rate variability and mortality risk in an elderly cohort. The Framingham Heart Study. Circulation. 1994;90:878-83. http://dx.doi.org/10.1161/01. CIR.90.2.878.

17 Tsuji H, Larson MG, Venditti FJ, Jr., Manders ES, Evans JC, Feldman CL, et al. Impact of reduced heart rate variability on risk for cardiac events. The Framingham Heart Study. Circulation. 1996; 94:2850-5. http://dx.doi.org/10.1161/01.CIR.94.11.2850.

18. Penn MS, Bakken EE. Heart-brain medicine: Update 2009. Cleve Clin J Med. 2010;77:S4-S6. http://dx.doi.org/10.3949/ ccjm.77.s3.01.

19. Steptoe A, Kivimaki M. Stress and Cardiovascular Disease: An Update on Current Knowledge. Annu Rev Public Health. 2013. http://dx.doi.org/10.1146/annurevpublhealth-031912-114452. 
20. Hemingway H, Shipley M, Brunner E, Britton A, Malik M, Marmot M. Does autonomic function link social position to coronary risk? The Whitehall II study. Circulation. 2005;111:3071-7. http://dx.doi.org/10.1161/ CIRCULATIONAHA.104.497347.

21. Juster R, McEwen B, Lupien S. Allostatic load biomarkers of chronic stress and impact on health and cognition. Neurosci Biobehav Rev. 2010;35:2-16. http://dx.doi.org/10.1016/j. neubiorev.2009.10.002.

22. Hartig T, Mang M, Evans GW. Restorative effects of natural environment experiences. Environ Behav. 1991;23:3-26. http://dx.doi.org/10.1177/0013916591231001

23. Berman MG, Jonides J, Kaplan S. The cognitive benefits of interacting with nature. Psychol Sci. 2008;19:1207-12. http:// dx.doi.org/10.1111/j.1467-9280.2008.02225.x

24. Barton J, Hine RE, Pretty J. The health benefits of walking in greenspaces of high natural and heritage value. J Integrative Environ Sciences. 2009;6:261-78. http://dx.doi. org/10.1080/19438150903378425

25. Barton J, Pretty J. What is the best dose of nature and green exercise for improving mental health? A multi-study analysis. Environ Sci Technol. 2010;44:3947-55. http://dx.doi. org/10.1021/es903183r

26. Barton J, Griffin M, Pretty J. Exercise, nature and socially interactive based initiatives improve mood and self-esteem in the clinical population. Perspect Public Health. 2012;132:8996. http://dx.doi.org/10.1177/1757913910393862.

27. Li Q, Otsuka T, Kobayashi M, Wakayama Y, Inagaki H, Katsumata M, et al. Acute effects of walking in forest environments on cardiovascular and metabolic parameters. Eur J Appl Physiol. 2011;111:2845-53. http://dx.doi.org/10.1007/ s00421-011-1918-z.

28. Gladwell VF, Brown DK, Barton JL, Tarvainen MP, Kuoppa P, Pretty J, et al. The effects of views of nature on autonomic control. Eur J Appl Physiol. 2012;112:3379-86.

29. Pretty J, Peacock J, Sellens M, Griffin M. The mental and physical health outcomes of green exercise. Int J Environ Heal R. 2005;15:319-37. http://dx.doi. org/10.1080/09603120500155963.

30. Park B, Tsunetsugu Y, Kasetani T, Kagawa T, Miyazaki Y. The physiological effects of Shinrin-yoku (taking in the forest atmosphere or forest bathing): evidence from field experiments in 24 forests across Japan. Environ Health Prev Med. 2010;15:1826. http://dx.doi.org/10.1007/s12199-009-0086-9.

31. Bowler DE, Buyung-Ali LM, Knight TM, Pullin AS. A systematic review of evidence for the added benefits to health of exposure to natural environments. BMC Public Health. 2010;10:456. http://dx.doi.org/10.1186/1471-2458-10-456.

32. Thompson Coon J, Boddy K, Stein K, Whear R, Barton J, Depledge $\mathrm{MH}$. Does participating in physical activity in outdoor natural environments have a greater effect on physical and mental wellbeing than physical activity indoors? A systematic review. Environ. Sci. Technol. 2011;45:1761-72. http://dx.doi. org/10.1021/es102947t.

33. Hartig T, Evans GW, Jamner LD, Davis DS, Gärling T.
Tracking restoration in natural and urban field settings. J Environ Psychol. 2003;23:10-23. http://dx.doi.org/10.1016/ S0272-4944(02)00109-3.

34. Department of Health [Internet]. Crown Copyright; [updated 2011 Jul 11; cited 2014 Jan 29]. UK Physical Activity Guidelines. Available from: https://www.gov.uk/government/ publications/uk-physical-activity-guidelines.

35. Brown DK, Barton JL, Pretty J, Gladwell VF. Walks4work: Rationale and study design to investigate walking at lunchtime in the workplace setting. BMC Public Health. 2012;12:550. http://dx.doi.org/10.1186/1471-2458-12-550.

36. D)Agostino RB, Sr., Vasan RS, Pencina MJ, Wolf PA, Cobain M, Massaro JM, et al. General cardiovascular risk profile for use in primary care: the Framingham Heart Study. Circulation. 2008;117:743-53. http://dx.doi.org/10.1161/ CIRCULATIONAHA.107.699579.

37. Sykes K, Roberts A. The Chester step test - a simple yet effective tool for the prediction of aerobic capacity. Physiotherapy. 2004;90:183-8. http://dx.doi.org/10.1016/j. physio.2004.03.008.

38. Brown DK, Grimwade D, Martinez-Bussion D, Taylor MJD, Gladwell VF. The Validity of the ActiPed for Physical Activity Monitoring. Int J Sports Med. 2013; 34:431-7.

39. Niskanen JP, Tarvainen MP, Ranta-Aho PO, Karjalainen PA. Software for advanced HRV analysis. Comput Meth Prog Bio. 2004;76:73-81. http://dx.doi.org/10.1016/j. cmpb.2004.03.004.

40. Batterham AM, Hopkins WG. Making meaningful inferences about magnitudes. Int J Sports Physiol Perform. 2006;1:50-7.

41. Gladwell V, Sandercock G, Birch S. Cardiac vagal activity following three intensities of exercise in humans. Clin Physiol Funct Imaging. 2010;30:17-22. http://dx.doi.org/10.1111/ j.1475-097X.2009.00899.x.

42. Chandola T, Heraclides A, Kumari M. Psychophysiological biomarkers of workplace stressors. Neurosci Biobehav Rev. 2010;35:51-7. http://dx.doi.org/10.1016/j. neubiorev.2009.11.005.

43. Kaplan R, Kaplan S. The experience of nature: A psychological perspective, Cambridge: Cambridge University Press, 1989.

44. Ulrich RS, Simons RF, Fiorito E, Miles MA, Zelson M. Stress recovery during exposure to natural and urban environments $\mathrm{J}$ Environ Psychol. 1991;11:201-30. http://dx.doi.org/10.1016/ S0272-4944(05)80184-7.

45. Thompson J, Webb R, Hewlett P, Llewellyn D, Mcdonnell B. Matrix Metalloproteinase-9 and Augmentation Index are Reduced with an 8-Week Green-Exercise Walking Programme. J Hypertens. 2013;2:127.

46. Hutchinson $\mathrm{AD}$, Wilson $\mathrm{C}$. Improving nutrition and physical activity in the workplace: a meta-analysis of intervention studies. Health Promot Int. 2011;2011:6.

47. Rhodes RE, Dickau L. Moderators of the intention-behaviour relationship in the physical activity domain: a systematic review. Br J Sports Med. 2013;47:215-25. http://dx.doi. org/10.1136/bjsports-2011-090411.

Received for publication:10 June 2013 